\title{
Malignant Lymphoma of the Bone Associated with Systemic Sarcoidosis
}

\author{
Hideo Kobayashi, Yoshiro Kato, Michiko Hakamada, Yoshihiko Hattori, Atsushi Sato, Naoko Shimizu, \\ Akira Imamura, Hidetsugu Mihara, Harumichi Kato, Yoshio OKI, Munehiko Morishita, \\ Hiroshi Miwa and Masakazu NitTA
}

\begin{abstract}
A 57-year-old woman was hospitalized with malignant lymphoma of the right talus. After treatment, complete remission was obtained. Gallium-67 scintigraphy to confirm the remission demonstrated increased uptake in the whole body skeletal muscle, especially in her thighs. Biopsy of right gastrocnemius muscle showed epithelioid granuloma. Serum angiotensin-converting enzyme activity (ACE) and lysozyme had increased to several times the normal range. We diagnosed her disease as bone-associated sarcoidosislymphoma syndrome. Human herpes virus 8 (HHV-8) genome was examined in the bone marrow specimen, and the relationship between sarcoidosis-lymphoma syndrome and HHV-8 was discussed.

(Internal Medicine 40: 435-438, 2001)
\end{abstract}

Key words: sarcoidosis-lymphoma syndrome, Ga-67 scintigraphy, HHV-8

\section{Introduction}

Sarcoidosis is in rare cases complicated by malignant lymphoma called sarcoidosis-lymphoma syndrome. This concept was proposed by Brincker who reported 46 cases in 1986 (1). In Japan, only 11 cases of sarcoidosis-lymphoma syndrome have been reported, and 4 of them were associated with lymphoma in stomach (2). We report a case of sarcoidosis-lymphoma syndrome in which lymphoma arose from the bone.

\section{Case Report}

A 57-year-old woman was admitted because of a few months history of right foot pain and swelling. An appendectomy had been performed in her childhood. The radiograph of the right ankle showed a compression fracture of the talus (Fig. 1), and gallium (Ga)-67 scintigraphy demonstrated increased uptake in the same lesion (Fig. 2). Biopsy of the right talus demonstrated malignant lymphoma of bone which was diffuse largeB cell type (Fig. 3). Bone marrow aspiration examination including chromosomal analysis of sternum was normal. HHV-8 virus genome was not detected in her sternum bone marrow specimen by nested PCR method (3). Laboratory findings showed a white blood cell count of $6,800 / \mathrm{mm}^{3}$ with normal differentiation, platelet count $244,000 / \mathrm{mm}^{3}$, red blood cell count $5.14 \times 10^{6} / \mathrm{mm}^{3}$, lactic dehydrogenase (LDH) $473 \mathrm{U} / l$, creatinine phosphokinase (CPK) $71 \mathrm{U} / l$, and creatinine $0.67 \mathrm{mg} / l$. Serum electrolyte levels were sodium $144 \mathrm{mEq} / l$, potassium $4.0 \mathrm{mEq} / \mathrm{l}$ and calcium $10.4 \mathrm{mg} / \mathrm{dl}$. $\beta 2$-microglobulin was 3.1 $\mathrm{mg} / \mathrm{l}$. Soluble IL2 receptor was $1,790 \mathrm{U} / \mathrm{ml}, \mathrm{IgG} 1,600 \mathrm{mg} / \mathrm{dl}$, IgA $328 \mathrm{mg} / \mathrm{dl}$ and IgM $225 \mathrm{mg} / \mathrm{dl}$. The skin reaction to PPD was negative. Chest $\mathrm{X}$-rays revealed moderate bilateral hilar lymphadenopathy. The ECG and echocardiogram were normal. Eye examination revealed no lesion.

The patient was given 6 courses of bi-weekly CHOP therapy ( $990 \mathrm{mg}$ of cyclophosphamide, $66 \mathrm{mg}$ of adriamycin, $1.8 \mathrm{mg} /$ day of vincristine day 1 , and $65 \mathrm{mg} /$ day of prednisolone days 1-5) (4) followed by $40 \mathrm{~Gy}$ irradiation of the right foot. The foot lesion improved, and the joint pain and swelling disappeared. However, a chest X-ray still showed moderate bilateral hilar lymphadenopathy, and the serum soluble interleukin-2 receptor level was not decreased. Ga-67 scintigraphy for confirmation of the remission revealed intense uptake in the whole body skeletal muscle, especially her thighs (Fig. 4). Biopsy of right gastrocnemius muscle showed epithelioid granuloma (Fig. 5). A diagnosis of sarcoidosis was made. Serum angiotensinconverting enzyme activity (ACE) (57.4 U/l) and lysozyme $(43.8 \mu \mathrm{g} / \mathrm{ml})$ were increased to several times the normal range. Serum aldolase was $6.2 \mathrm{U} / \mathrm{l}$. To date, a year after the onset of foot symptoms, sarcoidosis is asymptomatic without treatment.

From the Second Department of Internal Medicine, Aichi Medical University, Aichi

Received for publication January 6, 2000; Accepted for publication November 2, 2000

Reprint requests should be addressed to Dr. Yoshiro Kato, the Second Department of Internal Medicine, Aichi Medical University, 22 Karimata, Nagakute-cho, Aichi-gun, Aichi 480-1195 


\section{Discussion}

In the present case, we assumed that sarcoidosis subsisted when the patient showed the symptom of malignant lymphoma because her bilateral hilar lymphadenopathy remained after induction of complete remission of her lymphoma. Furthermore, intense uptake on Ga-67 scintigraphy in the skeletal muscle immediately after chemotherapy suggested that chemotherapy for her malignant lymphoma had advanced her sarcoidosis. Keohane et al reported a similar case in which sarcoi-

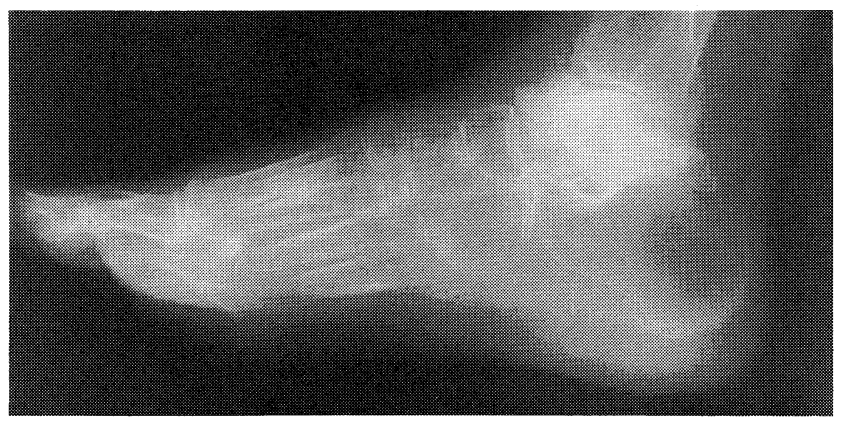

Figure 1. X-ray film of the right foot reveals compression fracture of the talus.

Figure 2. Gallium-67 scintigraphy on admission reveals intense uptake in the right foot.
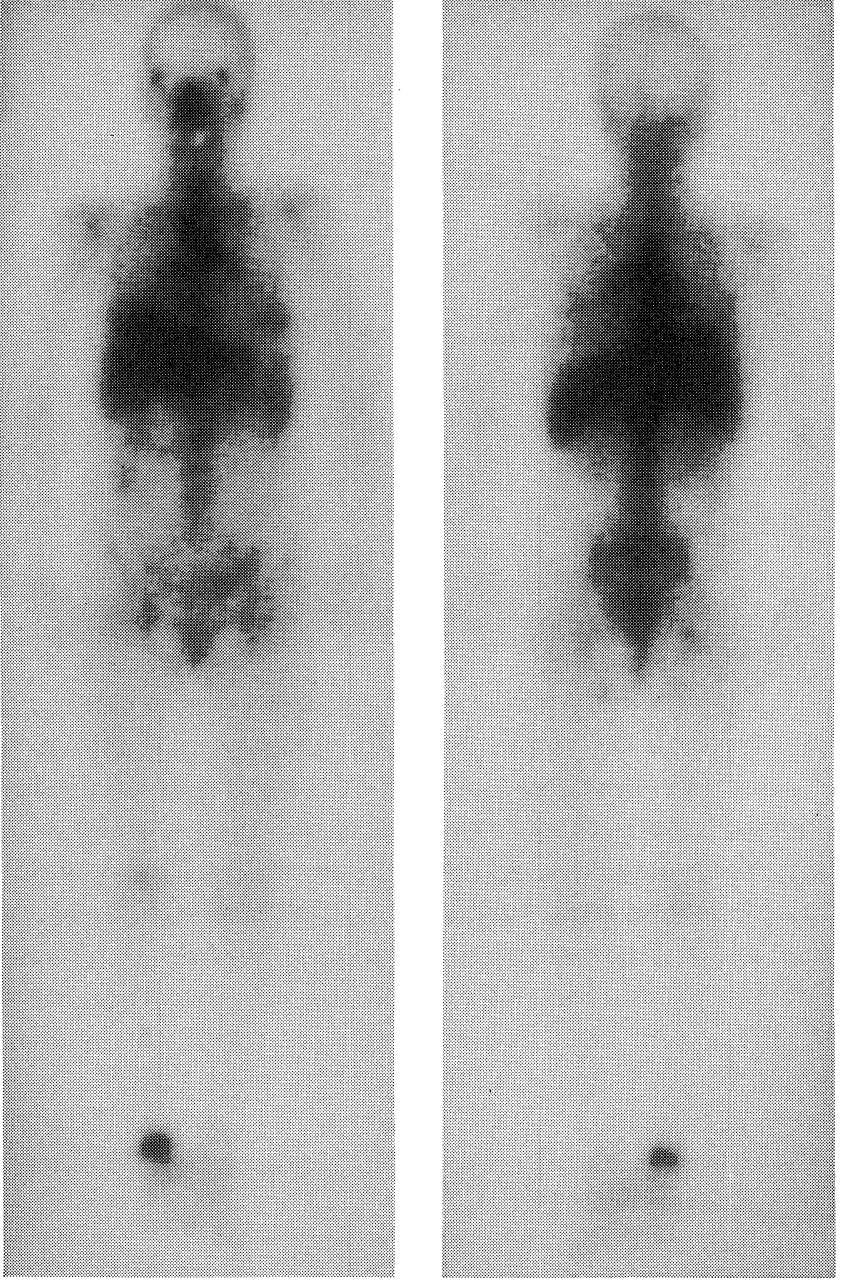

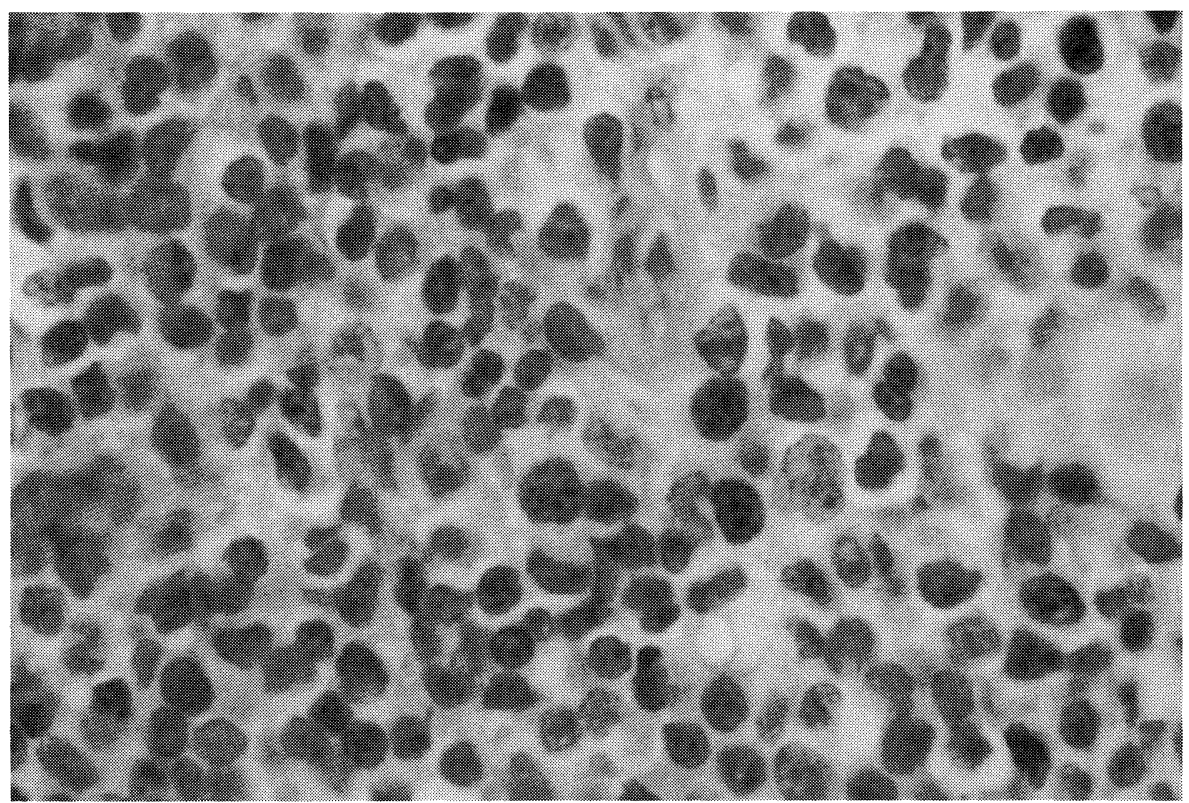

Figure 3. Microscopic findings of the right talus. Malignant cells show extensive infiltration in the bone marrow (HE stain, $\times 1,000)$. 


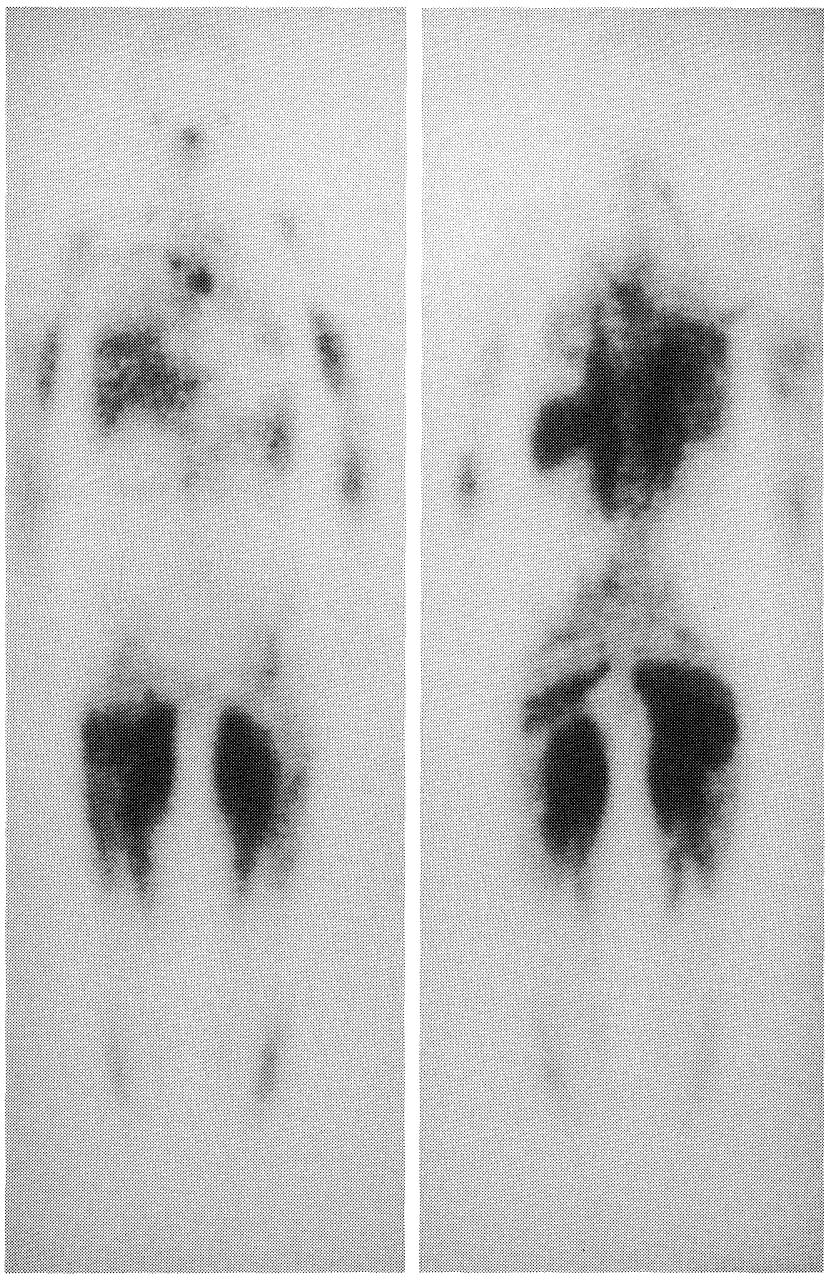

Figure 4. Gallium-67 scintigraphy after of 6 courses of biweekly CHOP treatment. The intense uptake is shown in the skeletal muscles.

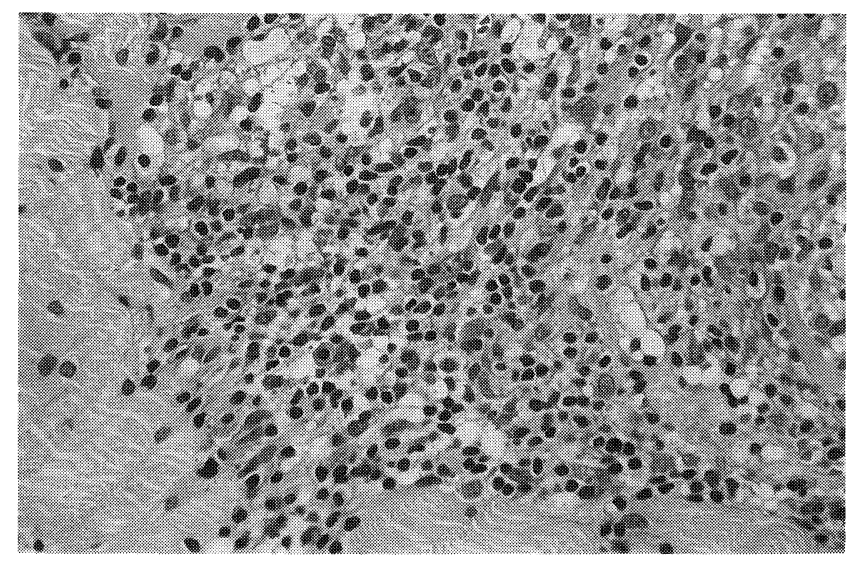

Figure 5. Sarcoid granuloma with giant cells seen in the biopsy specimen of the right gastrocnemius muscle (HE stain, $\times 400$ ). dosis was accelerated during chemotherapy of the lymphoma (5).

Only 11 cases of sarcoidosis-lymphoma syndrome have been reported in Japan in the past 12 years. Moreover, the type and site of lymphoma in this syndrome may differ with race. Brincker reported the association of Hodgkin's lymphoma in 18 of 46 cases (6). On the contrary, all of the cases were complicated with non-Hodgkin's lymphoma in Japan, and one-third of them were associated with gastric lymphoma. These findings may suggest the etiology is different with race in sarcoidosis-lymphoma syndrome. However, the incidence of Hodgkin's lymphoma is rare in Japan.

There are some hypothetical reasons for the association of malignant lymphoma with sarcoidosis (7). Sarcoidosis is characterized by the formation of generalized granulomas. According to the study by Lawrence et al, alveolar macrophage, $\mathrm{T}$ lymphocyte, and various cytokines such as interleukin-2 (IL2) are involved in granuloma formation of the lung (8). Lymphocytes in sarcoidosis are activated by several cytokines, and the proliferation potency is up-regulated (9). Disorganization and proliferation of lymphocytes under the continuous stimulation by antigens may induce malignant properties in the lymphatic system. Some investigators propose that propionibacterium is the antigen which stimulates the immune system and causes sarcoidosis (10).

Furthermore, a high incidence of infection of HHV-8 in the lymph nodes of sarcoidosis patients has recently been reported (11). HHV-8 is known to be associated with Kaposi's sarcoma and body cavity space lymphoma (BCSL) (12). This virus possesses genes resembling human IL-6, MIP, cyclin D and bcl-2 gene, and the products translated from these genes have biological activities in human cells (13). This suggests the possibility that the interaction of HHV-8 and other agents such as the propionibacterium for sarcoidosis might be involved in the pathogenesis of the sarcoidosis-lymphoma syndrome. It is known that about five percent of the entire Japanese population is positive for the HHV-8 antibody (14).

HHV-8 infection is an attractive hypothesis to explain the development of sarcoidosis-lymphoma syndrome, but two studies $(15,16)$ failed to confirm its involvement in sarcoidosis not associated with lymphoma. In the present patient, HHV-8 was not detected in the bone marrow, and the precise manner of HHV-8 infection in the human body remains to be elucidated. Further study of HHV-8 is needed to elucidate the possible association between the occurrence of malignant lymphoma and sarcoidosis involvement.

\section{References}

1) Brincker H. The Sarcoidosis-lymphoma Syndrome, Br J Cancer 54: 467473, 1986.

2) Takada K, Ina Y, Sato T, Morishita M, Yamamoto M. Sarcoidosis complicated by non-Hodgkin's lymphoma. Report of a case. Sarcoidosis 10: 134-137, 1993.

3) Cesarman E, Cang Y, Moore PS, Said JW, Knowles DM. Kaposi's sarcoma-associated herpes virus-like DNA sequences in AIDS-related bodycavity-based lymphoma. N Engl J Med 332: 1186-1191, 1995 (see com- 


\section{KOBAYASHI et al}

ments).

4) Tanosaki R, Okamoto S, Akatsuka N, et al. Dose escalation of biweekly cyclophosphamide, doxorubicin, vincristine, and prednisolone using recombinant human granulocyte colony stimulating factor in non-Hodgkin's lymphoma. Cancer 74: 7: 1939-1944, 1994.

5) Keohane SG, Savin JA, Tidman MJ, Anderson JA, Carey FA. The sarcoidosis-lymphoma syndrome: Acceleration of the cutaneous sarcoidosis during chemotherapy of the lymphoma. Acta Derm Venereol. 76 (3): 251253, 1996 (letter).

6) Brincker H. Coexistence of sarcoidosis and malignant disease: Causality or coincidence? Sarcoidosis 6: 31-43, 1989 (see comments).

7) Oliwiecki S, Kotecha B, Kingston T, Rothera MP. Sarcoidosis-lymphoma syndrome. J R Soc Med 85: 176-177, 1992.

8) Lawrence EC, Brousseau KP, Berger MB, Kurman CC, Marcon L, Nelson DL. Elevated concentrations of soluble interleukin-2 receptors in serum samples and bronchoalveolar lavage fluids in active sarcoidosis. Am Rev Respir Dis 137: 759-764, 1988.

9) Hunninghake GW, Garrett KC, Richerson HB, et al. Pathogenesis of the granulomatous lung disease. Am Rev Respir Dis 130: 476-496, 1984.
10) Ishige I, Usui Y, Takemura T, Eishi Y. Quantitative PCR of mycobacterial and propionibacterial DNA in lymph nodes of Japanese patients with sarcoidosis. Lancet 354 (9173): 120-123, 1999.

11) Di Alberti L, Piattelli A, Artese L, et al. Human herpes virus 8 variants in sarcoid tissues. Lancet 350: 1655-1661, 1997 (see comments).

12) Chang Y, Cesarman E, Pessin MS, et al. Identification of herpes viruslike DNA sequences in AIDS-associated Kaposi's sarcoma. Science 266: 1865-1869, 1994.

13) Nicholas J, Ruvolo VR, Burns WH, et al. Kaposi's sarcoma-associated human herpes virus-8 encodes homologues of macrophage inflammatory protein-1 and interleukin-6. Nat-Med 3 (3): 287-292, 1997.

14) Fujii T, Taguchi N, Nakamura T, Jyuji $T$, Iwamoto A. HHV-8 in Japan. (in Japanese) J J A Inf D 73: 194, 1999 (Abstract).

15) Belec L, Mohamed AS, Lechapt-Zalcman E, Authier FJ, Lange F, Gherardi RK. Lack of HHV-8 DNA sequences in srcoid tissues of French patients. Chest 114: 948-949, 1998 (letter).

16) Maeda $H$, Niimi $T$, Sato $S$, et al. Human herpes virus 8 in Japanese sarcoidosis. Am J Respir Crit Care Med 159: A342, 1999 (Abstract). 